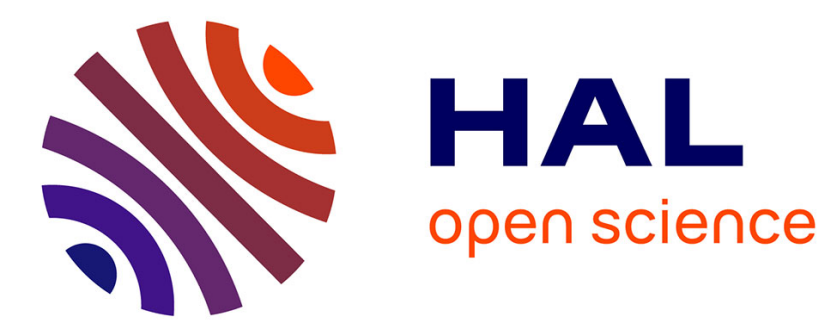

\title{
Preparation of high specific surface area hydroxyapatite for environmental applications
}

\author{
Cédric Verwilghen, Sébastien Rio, Ange Nzihou, Daniel Gauthier, Gilles \\ Flamant, Patrick Sharrock
}

\section{- To cite this version:}

Cédric Verwilghen, Sébastien Rio, Ange Nzihou, Daniel Gauthier, Gilles Flamant, et al.. Preparation of high specific surface area hydroxyapatite for environmental applications. Journal of Materials Science, 2007, 42 (15), p. 6062-6066. 10.1007/s10853-006-1160-y . hal-01634392

\section{HAL Id: hal-01634392 https://hal.science/hal-01634392}

Submitted on 1 Mar 2019

HAL is a multi-disciplinary open access archive for the deposit and dissemination of scientific research documents, whether they are published or not. The documents may come from teaching and research institutions in France or abroad, or from public or private research centers.
L'archive ouverte pluridisciplinaire HAL, est destinée au dépôt et à la diffusion de documents scientifiques de niveau recherche, publiés ou non, émanant des établissements d'enseignement et de recherche français ou étrangers, des laboratoires publics ou privés. 


\title{
Preparation of high specific surface area hydroxyapatite for environmental applications
}

\author{
Cedric Verwilghen - Sebastien Rio - Ange Nzihou • \\ Daniel Gauthier · Gilles Flamant · Patrick Joel Sharrock
}

\begin{abstract}
We report the preparation of hydroxyapatite in powdered form by aqueous reaction of calcium nitrate or hydroxide with phosphate ion at room temperature. With a slow maturation step of $48 \mathrm{~h}$ avoiding heat, the resulting products show large specific surface areas above $150 \mathrm{~m}^{2} / \mathrm{g}$. The specific surface areas also depend on stirring speed with a maximum observed with gentle mixing. Ageing causes a decrease in specific surface area which tends to stabilize near $100 \mathrm{~m}^{2} / \mathrm{g}$ following a 1 year period. The hydroxyapatite may be spray dried and conserve interesting physical properties for environmental applications.
\end{abstract}

\section{Introduction}

There is much interest in the synthesis of hydroxyapatite (HA) for various purposes [1, 2]. Synthetic HA is a calcium phosphate with close resemblance to the mineral phase of bone. Major efforts were devoted to the elaboration of bone substitutes based on artificially prepared calcium phosphates with high purity as required for medical purposes [3, 4]. It has long been known that HA has a large capacity for

C. Verwilghen $\cdot$ S. Rio $\cdot$ A. Nzihou

Centre RAPSODEE, UMR CNRS 2392, Ecole des Mines d'Albi,

Campus Jarlard, 81000 Albi, France

D. Gauthier - G. Flamant

PROMES CNRS Odeillo, 66125 Font Romeu, France

P. J. Sharrock $(\square)$

LCBM, Chemistry Department, Paul Sabatier University, Avenue G. Pompidou, B.P. 258, 81104 Castres, France

e-mail: patrick.sharrock@iut-tlse3.fr element substitution and this has triggered research on the use of HA for water purification, for waste stabilization, contaminated soil remediation, and heavy metal adsorption in general [5-7]. For environmental uses, the phase purity, crystalline structure and elemental impurities are not as much of a concern as are the cost of production and the heavy metal exchange capacity. For widespread use, natural apatites available in large quantities such as phosphate rock and natural fish bones have been investigated and subjected to field trials [8]. However, naturally occurring substances vary in nature and cannot have well tailored properties. This led us to seek a synthetic pathway for the production of HA which would be efficient, simple and yield a product with high reactivity towards heavy metals. In particular, our goal was to make a new adsorbent based on synthetic HA with large specific surface area for use in gas scrubber equipment. With this objective in mind we developed a low temperature precipitation reaction for $\mathrm{HA}$ in aqueous medium. This contrasts with the traditional methods of HA syntheses which always use heat, to warm the reaction solution or eliminate the nitrate by-products during calcinations [3, 4]. Compared to the usual synthesis methods, the novelty resides in the use of open vessels under air atmosphere and room temperature, which allows convenient production of large quantities. We present here the characteristics of the resulting $\mathrm{HA}$ as a function of reaction conditions.

\section{Materials and methods}

Two HA $\left(\mathrm{Ca}_{10}\left(\mathrm{PO}_{4}\right)_{6}(\mathrm{OH})_{2}\right)$ powders were prepared by wet methods using calcium nitrate [3, 4] or lime [9] as source of calcium. In the first case, a monoammonium phosphate solution $\left(\mathrm{NH}_{4}\right) \mathrm{H}_{2} \mathrm{PO}_{4}$ was mixed with a calcium 
nitrate solution, and the $\mathrm{pH}$ was maintained basic by addition of $\mathrm{NH}_{4} \mathrm{OH}$.

In the second case, phosphoric acid was added to a $\mathrm{Ca}(\mathrm{OH})_{2}$ solution. The $\mathrm{H}_{3} \mathrm{PO}_{4}$ addition rate was controlled using a peristaltic pump. The suspensions were continuously stirred at room temperature. After complete addition, the suspensions were matured for defined time spans (from $12 \mathrm{~h}$ to $120 \mathrm{~h}$ ) at various low temperatures $(25,40$ and $75^{\circ} \mathrm{C}$ ). Finally, the suspensions were washed, filtered and the resulting solids air dried at low temperatures under different conditions. Powders were obtained by ball milling and sieving to collect fractions below and above $80 \mu \mathrm{m}$.

More specifically, a laboratory batch was made using $210.63 \mathrm{~g}$ of calcium nitrate in $500 \mathrm{~mL}$ of water. The $\mathrm{pH}$ was adjusted to 10.7 with aqueous ammonia and the solution diluted to $1 \mathrm{~L}$ volume. Similarly, $67.66 \mathrm{~g}$ of ammonium nitrate at $\mathrm{pH} 10.3$ was dissolved in a total volume of $1.5 \mathrm{~L}$, and added to the calcium solution with stirring. This reaction was also scaled up by a factor of 20 in a $100 \mathrm{~L}$ reactor.

Another laboratory batch was made as follows: $77.18 \mathrm{~g}$ of calcium hydroxide were suspended in $2.5 \mathrm{~L}$ of demineralized water. $40 \mathrm{~mL}$ of $85 \%$ phosphoric acid were introduced over a $15 \mathrm{mn}$ period while stirring.

Powders were analyzed by X-ray diffraction (XRD) with a Philips Xpert working at $40 \mathrm{kV}$ and using the $\mathrm{CuK} \alpha$ radiation $(1.5406 \AA$ ). XRD diagrams were recorded in the interval $20^{\circ}<2 \theta<55^{\circ}$.

The specific surface area was measured by BET method using nitrogen adsorption at $77 \mathrm{~K}$ with a Micromeritics Vacrep 061. Powders were previously degassed at $100{ }^{\circ} \mathrm{C}$ under reduced pressure (50-100 mbar).

A Malvern Mastersizer 2000 was used to determine particle sizes and a Helium Accupyc 1330 from Micromeritics used for density measurements.

\section{Results and discussion}

\section{Hydroxyapatite synthesis}

There are two simple routes for the synthesis of HA in aqueous media. The standard method consists in precipitating HA under basic conditions from soluble calcium and phosphate salts. This is conveniently realized with calcium nitrate and ammonium phosphate, and by adjusting the $\mathrm{pH}$ with base as summarized in Eq. (1). The second method uses an acid-base reaction between phosphoric acid and calcium hydroxide, as shown in Eq. (2).

$$
\begin{gathered}
10 \mathrm{Ca}\left(\mathrm{NO}_{3}\right)_{2}, 4 \mathrm{H}_{2} \mathrm{O}+6 \mathrm{NH}_{4} \mathrm{H}_{2} \mathrm{PO}_{4}+14 \mathrm{NH}_{4} \mathrm{OH} \\
\rightarrow \mathrm{Ca}_{10}\left(\mathrm{PO}_{4}\right)_{6}(\mathrm{OH})_{2}+20 \mathrm{NH}_{4} \mathrm{NO}_{3}+52 \mathrm{H}_{2} \mathrm{O}
\end{gathered}
$$

$10 \mathrm{Ca}(\mathrm{OH})_{2}+6 \mathrm{H}_{3} \mathrm{PO}_{4} \rightarrow \mathrm{Ca}_{10}\left(\mathrm{PO}_{4}\right)_{6}(\mathrm{OH})_{2}+18 \mathrm{H}_{2} \mathrm{O}$

The problem with Reaction (2) is the difficulty in dissolving the calcium hydroxide and the rate of introduction of phosphoric acid which must remain slow enough to prevent from acidifying the reaction solution, which would result in the formation of calcium hydrogenophosphate. The main advantage is the absence of by-products. On the other hand, the precipitation is well controlled by the rate of addition of base in Reaction (1), but large amounts of nitrate salts are formed which must be water-washed to yield an impurity-free product.

Both reaction schemes were studied in parallel to compare the physico-chemical characteristics of the HA produced. Small laboratory samples were made, as well as larger $5 \mathrm{~kg}$ lots using a $100 \mathrm{~L}$ reactor. In every case, with proper mixing, the reaction proceeded smoothly and the formation of a white gelatinous precipitate was observed. $\mathrm{X}$-ray analysis of the collected, washed and dried precipitates show that hydroxyapatite was formed, with low crystallinity. Following sintering at high temperature, $\mathrm{X}$ ray diffraction confirms the presence of HA (JCPDS 9-432) with the presence of trace amounts of $\mathrm{CaO}$ (JCPDS 371497) (see Fig. 1).

SEM observations reveal the small grain sizes of the precipitates, less than 0.1 micrometer, while the sintered product shows larger sizes, near 0.5 micrometers as illustrated in Fig. 2.

Reaction conditions and specific surface areas

The effect of reaction times was investigated first because of its known influence on HA phase purity [10, 11, 12]. Results are presented in graphical form in Fig. 3. It appears that the calcium phosphate precipitates obtained have specific surface areas (SSA), which increase during the first two days of maturation and then stabilize between $120 \mathrm{~m}^{2} /$ $\mathrm{g}$ and $160 \mathrm{~m}^{2} / \mathrm{g}$.

The effect of reaction temperature is reported in Table 1 for the $48 \mathrm{~h}$ reactions. No significant effect on resulting SSA is observed due to temperature, but the preparation starting from the soluble calcium nitrate reached slightly higher SSA.

The influence of mixing speed was investigated by varying stirring conditions from 100 to 200, 300, 400 and $500 \mathrm{rpm}$. The results are presented in Fig. 4 and show that under our experimental conditions, $300 \mathrm{rpm}$ stirring yielded the highest SSA with a more pronounced effect for the calcium nitrate reaction.

One laboratory batch made with calcium nitrate was dried at various temperatures and the resulting SSA mea- 
Fig. 1 X-ray diffractogram for HA powder calcined at $1,000{ }^{\circ} \mathrm{C}$

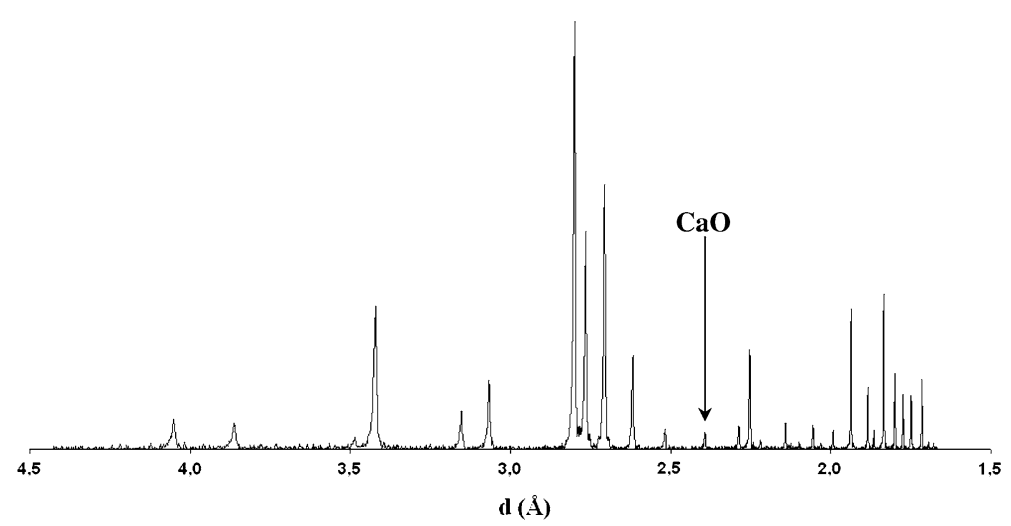

sured. Results presented in Fig. 5 pertain to a temperature interval where sintering does not yet occur [13]. Clearly, heating decreases the SSA and low temperature drying favors large SSA. Longer drying times (up to $24 \mathrm{~h}$ depending on sample size) are needed at low temperatures and large amounts of water, reaching $77 \%$ by weight, are observed.

Following synthesis and maturation, the standard procedure is to dry and grind the solids to obtain fine powder. An alternative spray drying process was tried to evaluate its effect on SSA. The results are gathered in Table 2. Basically, similar SSA values were obtained for spray drying
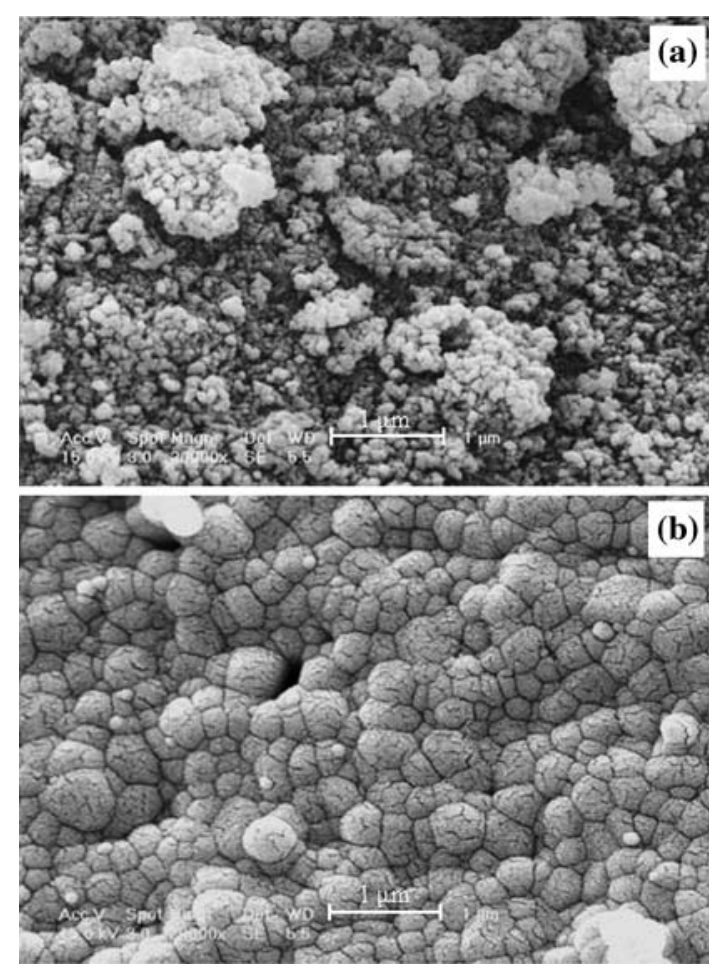

Fig. 2 SEM photographs of HA dried at $105^{\circ} \mathrm{C}$ (a) and calcined at $1,000{ }^{\circ} \mathrm{C}(\mathbf{b})$ and for air drying. Spray drying is interesting because it produces small monomodal spherical particles rapidly [14]. All the particle densities measured were similar and near $2.70 \pm 0.02 \mathrm{~g} / \mathrm{cm}^{3}$. The sprayed particles had lower diameters than the ball-milled ones.

Two samples obtained with standard air drying were followed as a function of time, while maintained in sealed screw capped vials at room temperature. The graph of the SSA as a function of time shows a progressive decrease of the SSA, which tends to stabilize near $100 \mathrm{~m}^{2} / \mathrm{g}$ following a 21 months period (see Fig. 6). Identical SSA results were observed with the larger scale batches made.

Hydroxyapatite formation mechanism

Our results can be interpreted as showing that submicron sized particles precipitate out of solution when calcium ions are mixed with orthophosphate ions at basic $\mathrm{pH}$. The colloidal particles are heavily impregnated with water and form a gel type material which dries slowly at room temperature. The composition of the kinetic product of the precipitation is in fact tricalcium phosphate (TCP) [10].

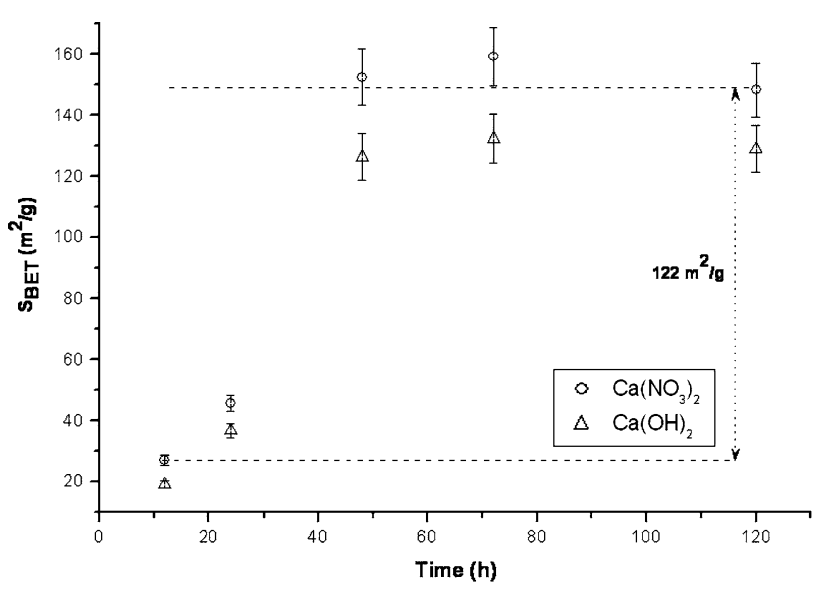

Fig. 3 Influence of reaction duration on Specific Surface Area 
Table 1 Specific Surface Area as function of synthesis temperature $\left(\mathrm{m}^{2} / \mathrm{g}\right) \pm 6 \%$

\begin{tabular}{llll}
\hline & $25{ }^{\circ} \mathrm{C}$ & $40{ }^{\circ} \mathrm{C}$ & $75{ }^{\circ} \mathrm{C}$ \\
\hline $\mathrm{Ca}\left(\mathrm{NO}_{3}\right)_{2}$ & 147 & 166 & 156 \\
$\mathrm{Ca}(\mathrm{OH})_{2}$ & 124 & 132 & 110 \\
\hline
\end{tabular}

The thermodynamic product, HA, forms slowly thereafter during maturation according to the stœchiometry of Eq. (3).

$$
3 \mathrm{TCP}+\mathrm{Ca}(\mathrm{OH})_{2} \rightarrow \mathrm{HA}
$$

The agglomeration of TCP precipitates eventually forms the HA particles, thus explaining the required maturation step. This can be accelerated by heating, but is not necessary. The formation of HA corresponds in fact to the incorporation of lime, and this can have an effect on suspension $\mathrm{pH}$. Excess calcium hydroxide contributes to HA formation but may lead to non-stœchiometric HA with

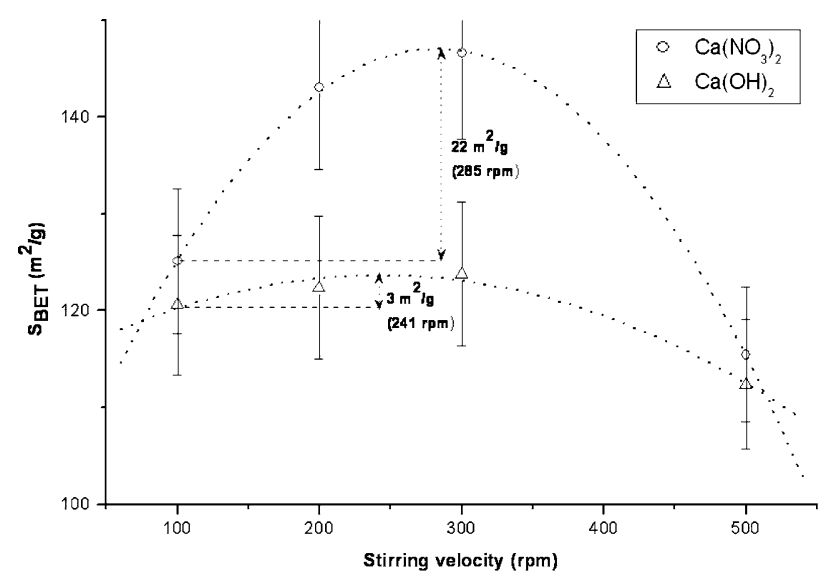

Fig. 4 Influence of stirring velocity on Specific Surface Area

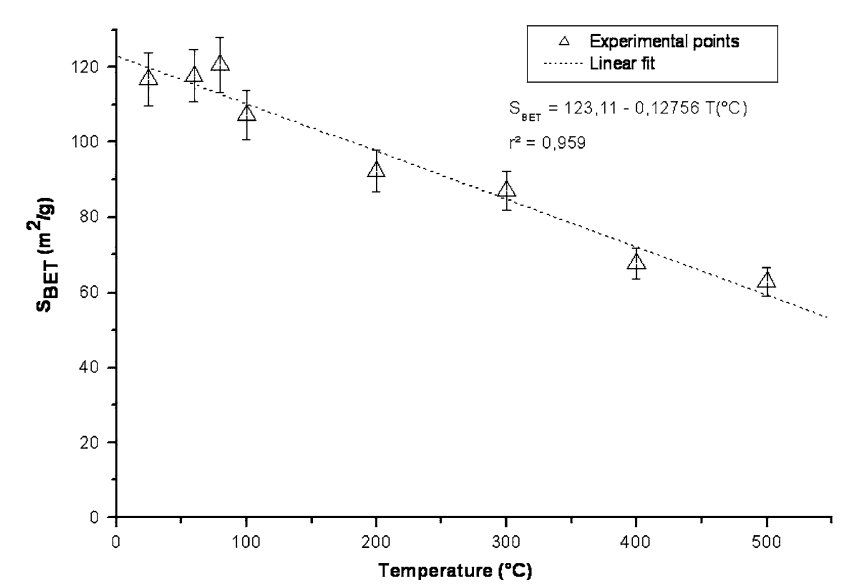

Fig. 5 Influence drying temperature on Specific Surface Area
Table 2 Specific Surface Area as function of drying step $\left(\mathrm{m}^{2} / \mathrm{g}\right)$

\begin{tabular}{|c|c|c|c|c|c|}
\hline & Drying & $\begin{array}{l}\text { Humidity } \\
(\%) \pm 0.2\end{array}$ & $\begin{array}{l}\text { Specific } \\
\text { Surface } \\
\text { Area }\left(\mathrm{m}^{2} / \mathrm{g}\right) \\
\pm 6 \%\end{array}$ & $\begin{array}{l}\text { Density } \\
\left(\mathrm{g} / \mathrm{cm}^{3}\right) \\
\pm 0.01\end{array}$ & $\begin{array}{l}\text { Median } \\
\text { diameter } \\
(\mu \mathrm{m}) \pm \\
0.5\end{array}$ \\
\hline \multirow[t]{3}{*}{$\mathrm{Ca}\left(\mathrm{NO}_{3}\right)_{2}$} & $\begin{array}{l}\text { Atomization } \\
\text { (3 bars) }\end{array}$ & 4.8 & 128 & 2.68 & 2 \\
\hline & $\begin{array}{c}60{ }^{\circ} \mathrm{C} \text { then } \\
105{ }^{\circ} \mathrm{C}\end{array}$ & 3.0 & 122 & 2.69 & 15 \\
\hline & $\begin{array}{c}25{ }^{\circ} \mathrm{C} \text { then } \\
105{ }^{\circ} \mathrm{C}\end{array}$ & 3.0 & 147 & 2.69 & 7 \\
\hline \multirow[t]{4}{*}{$\mathrm{Ca}(\mathrm{OH})_{2}$} & $\begin{array}{l}\text { Atomization } \\
\text { (3 bars) }\end{array}$ & 12.8 & 130 & 2.69 & 4 \\
\hline & $\begin{array}{l}\text { Atomization } \\
\text { (4 bars) }\end{array}$ & 11.9 & 118 & 2.70 & 4 \\
\hline & $\begin{array}{c}60{ }^{\circ} \mathrm{C} \text { then } \\
105{ }^{\circ} \mathrm{C}\end{array}$ & 2.5 & 114 & 2.70 & 12 \\
\hline & $\begin{array}{c}25{ }^{\circ} \mathrm{C} \text { then } \\
105{ }^{\circ} \mathrm{C}\end{array}$ & 3.0 & 124 & 2.72 & 12 \\
\hline
\end{tabular}

some calcium oxide present in the final product. Once the HA particles are formed, they will stick together to form larger crystallites, whether they are in suspension or in the solid state. Thus, too much stirring decreases the SSA, and heating also contributes to particle consolidation and SSA reduction. Low temperature synthesis and maturation is a viable route to high SSA HA which is much simpler than the emulsion based methods described in the literature for obtaining nanosized HA crystallites [15, 16].

\section{Conclusion}

Synthetic HA with SSA well above $100 \mathrm{~m}^{2} / \mathrm{g}$ may be obtained by purely aqueous precipitation route starting from widely available reactants. Best conditions include gentle stirring at room temperature, $48 \mathrm{~h}$ maturation, followed by

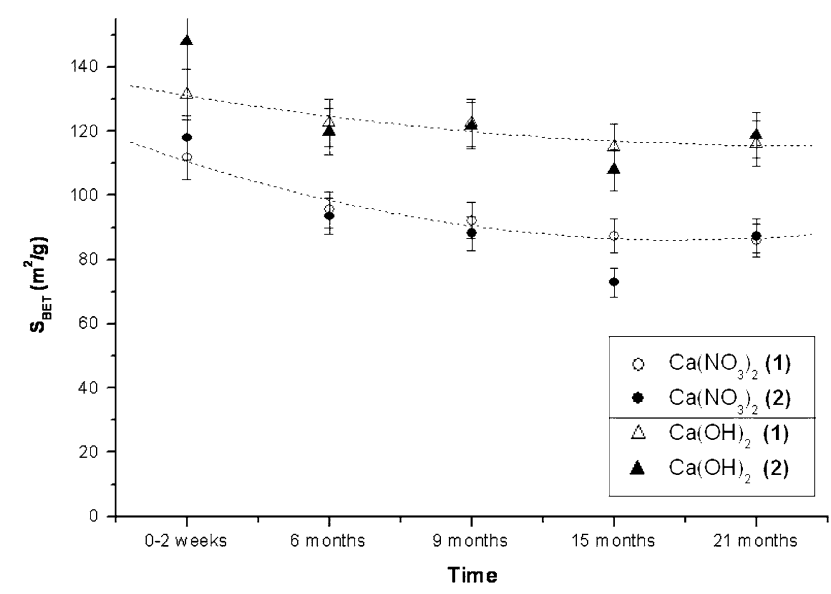

Fig. 6 Influence of ageing on Specific Surface Area 
low temperature drying or rapid spray drying. There is a $20 \%$ loss in the SSA of HA powders during a 1 year period, but all evidence shows that the particles maintain sufficient reactivity for use in adsorption reactions, and particularly heavy metal ion exchange and stabilization. Further work on this subject is in progress and shows promising results.

Acknowledegments We gratefully acknowledge help from Solvay HSE (Belgium) in the form of a research stipend. Our gratitude goes to ADEME (French Environment Agency) for funding this research under the grant No 02-74-111.

\section{References}

1. Narasaraju TSB, Phebe DE (1996) J Mat Sci 31:1

2. Elliot JC (1994) In: Structure and chemistry of the apatites and other orthophosphates (ed) Elsevier Amsterdam-London-New York-Tokyo (Studies in inorganic chemistry 18)
3. Jarcho M, Bolen CH (1976) J Mat Sci 11:2027

4. Hayek E, Newesely H (1963) Inorg Synthesis 7:63

5. Bailliez S, Nzihou A, Beche E, Flamant G (2004) Proce Safety Environ Protect 82(B2): 175

6. Chen X, Wright JV, Conca JL, Peurrung LM (1997) Environ Sci Technol 31:624

7. Da Rocha NC, De Campos RC, Rossi AM, Moreira EL, Barbosa F, Moure GT (2002) Environ Sci Technol 36:1630

8. Conca JL, Wright J (2001) Treatment of metal-contaminated leachates utilizing fish bones and fish hard parts. United States Patent 6217775

9. Osaka A, Miura Y, Takeuchi K, Asada M, Takahashi K (1991) J Mat Sci Mat In Med 2:51

10. Liu C, Huang Y, Shen W, Cui (2001) J Biomat 22:301

11. Liu DM, Troczynski T, Tseng WJ (2002) Biomaterials 23:1227

12. Rodriguez-Lorenzo LM, Vallet-Regi M (2000) Chem Mater 12(8): 2460

13. Baillez S, Nzihou A (2004) Chem Eng J 98:141

14. Luo P (1999) Methods of synthesizing hydroxylapatite powders and bulk materials. United States patent 5858318

15. Wu Y, Bose S (2005) Langmuir 21(8):3232

16. Bose S, Saha SK (2003) Chem Mater 15(23):4464 